\title{
The numerical simulation of thermal recovery based on hydraulic fracture heating technology in shale gas reservoir
}

\author{
Guang-pu Zhu ${ }^{\text {a }}$, Jun Yao ${ }^{\text {a }}$, Hai Sun ${ }^{\text {a, b }}$, Min Zhang ${ }^{\text {a }}$, Mei-jie Xie ${ }^{\text {a }}$, Zhi-xue Sun ${ }^{\text {a }}$ Tao Lu $^{\text {c }}$
}

\begin{abstract}
Shale gas reservoirs have received considerable attention for their potential in satisfying future energy demands. Technical advances in horizontal well drilling and hydraulic fracturing have paved the way for the development of shale gas reservoirs. Compared with conventional gas reservoir, adsorbed gas accounts for a large proportion of total gas within shale, so the amount of gas desorbed from the formation has a large impact on the ultimate gas recovery. Recently, efforts toward the thermal recovery of shale oil based on hydraulic fracture heating technology (ExxonMobil's Electrofrac) have made some progress. However, the temperature-dependent adsorption behavior and its major applications of evaluating thermal stimulation as a recovery method have not been thoroughly explored. Additionally, many complicated nonlinear processes coexist in shale formation such as Knudsen diffusion, the pressure dependent phenomenon and non-Darcy flow, presenting a significant challenge for quantifying flow in shale gas reservoir.
\end{abstract}

To investigate the effect of thermal recovery based on hydraulic fracture heating, a fully coupled numerical model of a fractured horizontal well is developed to capture the real gas flow in shale gas reservoir. Discrete fracture, dual continuum media and single porosity media are employed to describe the hydraulic fractures, the stimulated reservoir volume (SRV) region and the matrix, respectively. The model incorporates non-linear flow mechanisms including adsorption/desorption, Knudsen diffusion, non-Darcy flow and pressure dependent phenomenon, as well as heat diffusion processes within the shale reserve. Then, the effectiveness of formation factors on thermal recovery is analyzed.

The results show that hydraulic fracture heating can actually enhance shale gas recovery by altering gas desorption behavior, and that this method is more suitable for long-term production. More adsorbed gas can be recovered with increasing simulation temperature. The thermal properties of the shale formation only have limited impacts on the long-term production. The gas production rate is primarily determined by the simulation temperature, matrix adsorption ability, fracture spacing, area of the SRV region, bottom hole pressure (BHP) and reservoir permeability. A shale gas reservoir with a large Langmuir volume and SRV area, relatively small fracture spacing, and a high BHP has the potential for thermal treatment to enhance gas recovery. The fracture temperature, the area of the SRV region and the fracture spacing are the only three factors that can be controlled during the design and execution of thermal treatment in the field.

Keywords: Thermal recovery; Shale gas reservoir; Hydraulic fracture; Desorption; Discrete fracture; Numerical simulation

E-mail addresses: zhugp19911202@163.com (G.-p. Zhu), rcogfr_upc@126.com (J. Yao), sunhaiupc@ sina.com (H. Sun), zgsydxzmin@126.com (M. Zhang), carolxiemj@163.com (M.-j. Xie), Szx1979@126.com (Z.-x. Sun), Lutao_cq@petrochina.com.cn (T. Lu).

Phone number: +8618765922794 (G.-p. Zhu) 


\section{Introduction}

Shale gas reservoirs have received considerable attention around the world for their abundant resources and the application of technologies such as horizontal well drilling, micro-seismic fracture diagnosis and hydraulic fracturing (Dongyan et al., 2015). Although the amount of gas production in shale gas reservoirs is growing rapidly, the understanding and technologies required for effective development of shale gas reservoir are far behind the industry needs. Gas recovery remains very low (estimated at $10 \%$ to $30 \%$ of gas in place) (Wu et al., 2014) . Shale gas reservoir are characterized by extremely low matrix permeability and highly complex network of natural fractures, in which many complicated nonlinear processes coexist, such as Knudsen diffusion, pressure dependent phenomenon, non-Darcy flow and adsorption/desorption (Eshkalak et al., 2014; Javadpour et al., 2007; Sun et al., 2013; Wu et al., 2014). However, developing an unconventional reservoir model that accounts for pressure dependent phenomenon and integrates all physics incorporated in gas flow for shale formations is still a challenging target for the petroleum industry (Eshkalak et al., 2014). To improve the gas recovery, we must have better understanding of how these nonlinear flow behavior impact the ultimate gas recovery. One important aspect of shale gas reservoir that needs special consideration is adsorption/desorption.

Natural gas in shale gas formation is mainly present both as free gas stored in matrix and natural fractures, and as gas adsorbed onto matrix surfaces. According to the research of many scholars, the amount of adsorption gas varies from $20 \%$ to $85 \%$ of the total gas within shale which cannot be neglected in modeling analysis (Curtis, 2002; Martini et al., 2003; Wu et al., 2014). The gas adsorption behavior in shale-gas system is primarily determined by total organic carbon (TOC), pressure and formation temperature. Previous studies found that methane molecules are mainly adsorbed to organic matter (i.e., kerogen), and that gas adsorption capacity increases with increasing TOC content (Hildenbrand et al., 2006; Wu et al., 2014). Formation pressure largely impacts the adsorption behavior. Experiments found that with increasing reserve pressure, the adsorption capacity gradually increased. In particular, in a specified range of low pressure, there was a dramatic rise in adsorption capacity with increasing pressure (Chalmers and Bustin, 2008). The gas reservoir pressure must be sufficiently low to liberate the adsorbed gas. However, it would take considerable production time for the average pressure to decrease to a level where most of the adsorbed gas can be liberated due to the extremely low porosity and permeability, and the production rate may have already reached the economical shut-in limits. Temperature also plays an important role in determining how much gas is ultimately adsorbed on the matrix surface. A high formation temperature may lead to extremely low adsorption capacity of methane. For a formation with temperature up to $400 \mathrm{~K} \sim 423 \mathrm{~K}$, the adsorption capacity of methane is lower than $0.01 \mathrm{~cm}^{3} / \mathrm{g}$ (Ross and Bustin, 2007). Thus thermal stimulation techniques that can increase the formation temperature around the hydraulic fracture during production can be utilized as a potential method to enhance the ultimate recovery of the shale gas reservoir by altering the shale gas desorption behavior (Wu et al., 2014). This will significantly enhance the desorption rate and recovery before reaching reservoir pressure economic limits.

Thermal recovery technology has been widely applied in the petroleum industry especially in heavy oil and bituminous sands with the intention of reducing oil viscosity, and 
increasing oil mobility. Numerous authors have investigated the thermal recovery method as cyclic steam stimulation, steam injection, in-situ combustion, steam assisted gravity drainage, vapor extraction and expanding solvent steam assisted gravity drainage (Ghoodjani et al., 2012). Recently, the study of thermal recovery in unconventional resource area has attracted some interest. ExxonMobil Company proposed an Electrofrac process for in situ oil conversion (Symington, 2006). The method heats the shale oil in situ by hydraulically fracturing the shale and filling the fractures with electrically conductive material to form a resistive heating element. Kerogen in the oil shale converts to oil and gas that is produced conventionally. Their laboratory experiments found that calcined petroleum coke is a suitable conductive material for use as a fracture heating element. Additionally, electrical continuity of the fracture heating element is unaffected by kerogen conversion. The temperature in the hydraulic fracture could be stimulated even up to $673 \mathrm{~K}$. In 2009, ExxonMobil conducted a low-temperature field experiment at the Colony Mine in northwestern Colorado (Symington et al., 2009). The experiment verified that an electrically conductive fracture can be constructed in the field and operated at low temperatures for a period of several months. The data acquired from the experiment, including temperature, voltage, electric current, and rock motion presents a unique opportunity to develop and calibrate in situ oil shale modeling capabilities. In 2010, numerical models were developed to analyze and interpret the thermal and electrical data collected during the field experiment (Hoda et al., 2010). The combination of electrical and thermal models provides a powerful tool for analyzing this low-temperature field experiment and for predicting the behavior of future tests. Their explorations provide vast prospects for thermal stimulation of unconventional resource. Another possible method to heat the hydraulic fracture directly is to use nanoparticles for increased unconventional resource production via enhanced electromagnetic heating of hydrocarbon deposits and decreased oil viscosity (Mutyala et al., 2010; Yahya et al., 2012). However, studies have only focused on improving heavy oil/shale oil recovery by increasing the formation temperature to convert kerogen into oil/gas and to reduce the oil viscosity. Is there a possibility that altering the adsorption behavior can enhance shale gas recovery by increasing the temperature within the hydraulic fractures with similar methods? Meanwhile, the numerical simulation of thermal recovery of unconventional resource has made some progress. Thoram and Ehlig-Economides (2011) proposed injecting high-quality saturated steam generated using a small-scale nuclear plant for heating the SRV region to the necessary temperature at which kerogen can be decomposed into oil and gas. Additionally, produced water would be reheated and reinjected in a closed cycle. Wang et al. (2014) developed a fully coupled model to investigate the effects of fracture heating on the shale gas desorption phenomenon on global well performance and recovery. Their results indicate that by increasing the temperature of the fracture, shale gas recovery can be improved. However, their model may not be suitable for realistic application because it neglects the widely-distributed natural fractures and complicated nonlinear process such as Knudsen diffusion, non-Darcy flow, and pressure dependent phenomenon. Their explorations provide reference for our thermal recovery modeling of shale gas reservoir.

To investigate the performance of thermal recovery based on hydraulic fracture heating, a fully coupled numerical model of a fractured horizontal well is developed to capture the real gas flow in shale gas reservoir. Discrete fracture (Fu et al., 2005; Geiger-Boschung et al., 
2009; Karimi-Fard and Firoozabadi, 2001; Karimi-Fard and Firoozabadi, 2003; McLennan et al., 2010; Moinfar et al., 2013; Zhao et al., 2011), dual continuum media (Dean and Lo, 1988; Thomas et al., 1983; Warren and Root, 1963) and single porosity media are employed to describe hydraulic fractures, the SRV region and the matrix, respectively. The model incorporates non-linear flow mechanisms including adsorption/desorption on the matrix surface, Knudsen diffusion in the matrix, non-Darcy flow of hydraulic fracture and pressure dependent phenomenon of natural fractures, as well as heat diffusion processes within the shale reserve. The main factors determining whether increasing the formation temperature can be successful are also discussed. The results of this study can provide a foundation for future research endeavors involving on cost-effective thermal stimulation techniques to enhance shale gas recovery. The technical route is shown in Fig. 1.

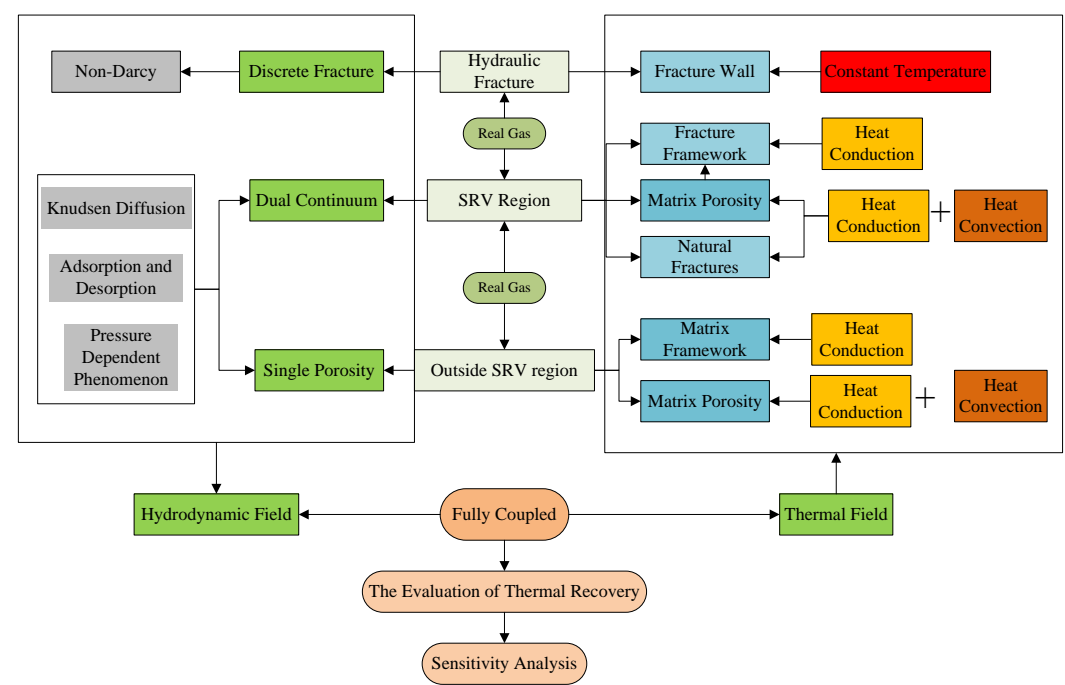

Fig. 1. Technical route of thermal recovery

\section{Thermal recovery model and numerical solution}

Considering a fractured horizontal well in a three-dimensional closed, box-shaped shale gas reservoir, hydraulic fractures are symmetrically and vertically distributed around the horizontal well and are surrounded by the stimulated reservoir volume (SRV) region, as shown in Fig. 2. The dimensions of the reservoir model are $2000 \mathrm{~m} \times 2000 \mathrm{~m} \times 50 \mathrm{~m}$, the dimensions of the SRV model are $800 \mathrm{~m} \times 400 \mathrm{~m} \times 50 \mathrm{~m}$. The assumptions are as follows: (1) the reserve is homogeneous and the gravity force is neglected. (2) Only single component methane exists in the matrix, natural fractures and hydraulic fractures. There is only free gas in natural fractures. Adsorbed gas and free gas coexist in the matrix. (3) Natural fractures are opened and connected. The SRV region is consists of matrix and micro-fractures and can be described with dual porosity model. The permeability of matrix system is very low compared with micro-fracture system. (4) The matrix characteristics outside the SRV region are the same as in the unstimulated and stimulated reservoir, i.e., permeability and porosity. 


\section{Fig. 2. The schematic of a fractured horizontal well in composite gas reservoir}

\subsection{The hydraulic fracture model}

Low-viscosity gas has high flow velocity, especially in adjacent wellbore and hydraulic fractures where the pressure gradient is larger. The turbulent flow of methane in hydraulic fractures that results from the inertia force can be described by the Forchheimer equation, which adds a non-linear term compared to Darcy's law:

$$
-\nabla p_{\mathrm{a}}=\frac{\mu}{k_{\mathrm{a}}} v_{a}+\rho \beta v_{a}^{2}
$$

The Forchheimer equation can be represented as a correction formula of Darcy's law, given by equation (2):

$$
v_{a}=-\frac{k_{\mathrm{a}}}{\mu} \delta \nabla p_{\mathrm{a}}
$$

where $\delta$ is the non-Darcy flow correction factor which is relative to the gas flow velocity, and is commonly written as

$$
\delta=\frac{1}{1+\frac{k_{a}}{\mu} \rho_{a} v_{a} \beta}
$$

where $\beta$ is the Forchheimer coefficient. Evans and Civan's empirical correlation (Evans and Civan, 1990) is used to describe it:

$$
\beta=\frac{4.87 \times 10^{c}}{k_{a}^{1.021}}
$$

The exponent $c$ has different values, and is dependent on the inertial effect. When the gas flow velocity is low, i.e., $\delta=1$, the Forchheimer equation reverts to Darcy's equation.

Thus, the continuity equation of hydraulic fractures can be presented as

$$
\frac{\partial}{\partial t}\left(\rho_{a} \varphi_{a}\right)+\nabla \cdot\left(\frac{\delta k_{a}}{\mu_{a}} \nabla p_{a}\right)=q_{a} \delta\left(M-M^{\prime}\right)
$$

where $\rho_{a}$ is the gas density in the hydraulic fractures, $\mathrm{kg} / \mathrm{m}^{3} ; \varphi_{a}$ is the porosity of the hydraulic fracture; $q_{a}$ is the source/sink term; $\mu_{a}$ is the gas viscosity in hydraulic fracture, $\mathrm{Pa} \cdot \mathrm{s}$; $v_{a}$ is the gas flow velocity, $\mathrm{m} / \mathrm{s} ; k_{a}$ is the permeability in hydraulic fracture, $\mathrm{m}^{2} . M$ is an any formation point and $M^{\prime}$ is the intersection point of the hydraulic fractures with the wellbore, and $\delta\left(M-M^{\prime}\right)$ is a delta function, the value is one at $M=M^{\prime}$ or zero in other cases.

During the thermal recovery process of shale gas reservoir, changes in temperature and 
pressure will greatly affect gas properties. The traditional ideal gas model may be not suitable in modeling the long-term production of shale gas. It is therefore necessary to develop a real gas-based numerical model of thermal stimulation in shale gas reservoir. Lee et al. (1966) proposed a correlation to calculate gas viscosity:

$$
\left\{\begin{array}{l}
K=\frac{(22.7+48.3) T^{1.5}}{209+19000 M_{g}+1.8 T} \\
X=3.5+\frac{547.8}{T}+10 M_{g} \\
Y=2.4-0.2 X \\
\mu=10^{-7} K \mathrm{e}^{X(0.001 \rho)^{Y}}
\end{array}\right.
$$

where $M_{g}$ represents the methane molar weight, $\mathrm{kg} / \mathrm{mol} ; T$ is the gas reservoir temperature, $\mathrm{K}$.

The $\mathrm{Z}$ factor can be calculated with the pseudo reduced pressure and pseudo reduced temperature of methane by the correlation introduced by Mahmoud (2014).

$$
Z=0.702 e^{-2.5 T r} p_{r}^{2}-5.524 e^{-2.5 T r} p_{r}+0.044 T_{r}^{2}-0.164 T_{r}+1.15
$$

Gas density can be calculated by $\rho=p M_{g} /(\mathrm{ZR} T)$.

Thus, equation (5) can be simplified as

$$
\phi_{a} \rho_{a} c_{a g} \frac{\partial p_{a}}{\partial t}-\nabla \cdot\left[\frac{\rho_{a} k_{a}}{\mu_{a}} \nabla p_{a}\right]=q_{a} \delta\left(M-M^{\prime}\right)
$$

where $C_{a g}$ is the gas compressibility factor in the hydraulic fracture, $\mathrm{Pa}^{-1} \cdot \mathrm{s}$, and it can be represented as

$$
C_{a g}=\frac{1}{p_{a}}-\frac{1}{Z_{a}} \cdot \frac{d Z_{a}}{d p_{a}}
$$

The pressure on hydraulic and natural fractures boundaries is equal, and the mathematical model of the hydraulic fracture is given by

$$
\left\{\begin{array}{l}
\phi_{a} \rho_{a} c_{a g} \frac{\partial p_{a}}{\partial t}-\nabla \cdot\left[\frac{\rho_{a} k_{a}}{\mu_{a}} \nabla p_{a}\right]=q_{a} \delta\left(M-M^{\prime}\right) \\
p_{a}(x, y, z ; t=0)=p_{i} \\
\left.p_{a}\right|_{\Gamma_{4}}=p_{w} \\
\left.p_{a}(x, y, z ; t)\right|_{\Gamma_{3}}=\left.p_{f}(x, y, z ; t)\right|_{\Gamma_{3}}
\end{array}\right.
$$

where $p_{i}, p_{w}$ represents the initial pressure and BHP, respectively, $\mathrm{Pa} ; \Gamma_{3}, \Gamma_{4}$ are defined as the boundary between hydraulic and natural fracture, and the inner boundary of the horizontal well, respectively.

\subsection{The SRV region model}

The main gas transport mechanism in tight porous media follows the viscosity flow, Knudsen diffusion, and adsorption/desorption. Viscous flow is the dominant transport mechanism in shale gas reservoirs, and the net flux generated by very small pressure gradients 
will exceed that caused by very large concentration gradients (Freeman et al., 2011). The gas flux caused by viscous flow can be modeled by Darcy's law. Knudsen diffusion occurs when the mean free path of gas molecules is at the same scale as the pore size of the porous medium. In shale gas reservoirs, the pore diameters mainly range from $4 \mathrm{~nm}$ to $200 \mathrm{~nm}$ (Javadpour et al., 2007), which are of similar magnitude as the mean free path of methane molecules. Therefore, Knudsen diffusion is significant in shale gas reservoirs and cannot be ignored. The gas flux generated by Knudsen diffusion is (Akkutlu and Fathi, 2012)

$$
N_{k}=-M_{g} D_{k m} \nabla C_{m}=-M_{g} D_{k m} \nabla\left(\frac{p_{m}}{Z R T}\right)=-\frac{\rho_{m} D_{k m} \nabla p_{m}}{p_{m}}
$$

where $D_{k m}$ represents the diffusion coefficient of the matrix (Civan, 2010; Javadpour et al., 2007), and which can be expressed as

$$
D_{k m}=\frac{4 k_{m i} c_{k}}{2.81708 \sqrt{\frac{k_{m i}}{\varphi_{m}}}} \sqrt{\frac{\pi R T}{2 M_{g}}}
$$

where $N_{k}$ is the mass flow caused by Knudsen diffusion, $\mathrm{kg} /\left(\mathrm{m}^{2} \cdot \mathrm{s}\right) ; C_{m}$ represents the gas molar concentration, $\mathrm{mol} / \mathrm{m}^{3} ; \varphi_{m}$ is the matrix porosity; $\mathrm{R}$ is the universal gas coefficient, $\mathrm{R}=8.314 \mathrm{~K}^{-1} \cdot \mathrm{mol}^{-1} ; k_{m i}$ is the intrinsic permeability of matrix, $\mathrm{m}^{2}$; and $c_{k}$ is a constant 1 , dimensionless (Freeman et al., 2011).

\subsubsection{The continuity equation of the matrix}

Natural gas in the shale matrix is present both as free gas stored in the matrix porosity, and as gas adsorbed onto matrix surfaces. Viscous flow, Knudsen diffusion and adsorption/desorption are considered. According to the principle of mass balance, the continuity equation of the matrix system (Eshkalak et al., 2014; Wu et al., 2014) can be presented as:

$$
\frac{\partial}{\partial t}\left[\rho_{m} \phi_{m}+\left(1-\phi_{m}\right) q_{a d s}\right]+\nabla \cdot F_{m}=-Q_{p}
$$

where $F_{m}$ is the gas mass flow rate of the matrix (Freeman et al., 2011; Kast and Hohenthanner, 2000)

$$
F_{m}=-\frac{\rho_{m} k_{m i}}{\mu_{m}} \nabla p_{m}-M_{g} D_{k m} \nabla C_{m}=-\frac{\rho_{m} k_{m i}}{\mu_{m}} \nabla p_{m}-\frac{\rho_{m} D_{k m} \nabla p_{m}}{p_{m}}=-\frac{\rho_{m} k_{m}}{\mu_{m}} \nabla p_{m}
$$

$k_{m}$ is the matrix permeability, which can be represented as

$$
k_{m}=k_{m i}\left(1+\frac{\mu_{m} D_{k m}}{p_{m} k_{m i}}\right)
$$

$q_{a d s}$ is the gas adsorption mass per unit volume of formation, $\mathrm{kg} / \mathrm{m}^{3}$. During the thermal recovery process, Langmuir isothermal equation is not suitable because of the drastic temperature changes. Thus, the adsorption model (Adamson and Gast, 1997; Ruthven, 1984) based on the theory of kinetics and thermodynamics is introduced into the model:

$$
q_{a d s}=\frac{\rho_{s} M_{g} V_{L}}{V_{s t d}} \frac{K(T) p_{m}}{1+K(T) p_{m}}
$$


$K(T)$ is the adsorption equilibrium equation constant, $1 / \mathrm{Pa}$, which can be considered to

where $k_{0}$ is a pre-exponential constant independent of temperature, $1 / \mathrm{Pa} ; E$ is the characteristic adsorption energy, $\mathrm{J} / \mathrm{mol} ; V_{L}$ is the Langmuir volume, $\mathrm{m}^{3} / \mathrm{kg} ; \rho_{s}$ is the shale matrix density, $\mathrm{kg} / \mathrm{m}^{3}$; and $V_{\text {std }}$ is the molar volume under standard condition, $\mathrm{m}^{3} / \mathrm{mol}$.

Considering the pseudo steady state interporosity flow between the matrix and natural fracture system:

$$
Q_{p}=\frac{\rho_{g} k_{m} \alpha_{P S S}\left(p_{m}-p_{f}\right)}{\mu_{m}}
$$

where $\alpha_{P S S}$ is the shape factor, which can be expressed as

$$
\alpha_{P S S}=4\left(\frac{1}{L_{x}^{2}}+\frac{1}{L_{\mathrm{y}}^{2}}+\frac{1}{L_{\mathrm{z}}^{2}}\right)
$$

$L_{x}, L_{y}$ and $L_{z}$ represent natural fractures spacing in coordinate directions, respectively, $\mathrm{m}$. Substituting equation (14), (15), (16) and (17) into equation (13), yields

$$
\begin{aligned}
& {\left[\phi_{m} \rho_{m} C_{m g}+\left(1-\phi_{m}\right) \frac{\rho_{s} M_{g} V_{L}}{V_{s t d}} \cdot \frac{p_{m}}{\left(1+K(T) \cdot p_{m}\right)^{2}}\right] \frac{\partial p_{m}}{\partial t}-\nabla \cdot\left[\frac{\rho_{m} k_{m}}{\mu_{m}} \nabla p_{m}\right]} \\
& =\left(1-\phi_{m}\right) \frac{\rho_{s} M_{g} V_{L}}{V_{s t d}} \cdot \frac{p_{m}}{\left(1+K(T) \cdot p_{m}\right)^{2}} \cdot K(T) \cdot\left[-\frac{1}{2 T}+\frac{E}{R T^{2}}\right] \cdot \frac{\partial T}{\partial t}-Q_{p}
\end{aligned}
$$

\subsubsection{The continuity equation of natural fractures}

The decrease of formation pressure has a significant effect on the permeability and porosity of the shale reserve in the development of shale gas reservoir. Theoretical research and experiments have been conducted to analyze fracture sensitivity to change in the effective stress profile in the shale gas reservoir with continued production (Dong et al., 2010; Eshkalak et al., 2014; Soeder, 1988). These studies demonstrate the relationship between permeability and pore pressure change, which satisfies an exponential mathematical expression:

$$
k_{f}=k_{f 0} e^{-\gamma\left(p_{i}-p_{f}\right)}
$$

$k_{f 0}$ is the intrinsic permeability of natural fractures, $\mathrm{m}^{2}$.

Due to the millimeter scale of the average pore diameters in the fracture system, the effect of Knudsen diffusion is notably small and only permeability dependent phenomenon and viscous flow are incorporated into the natural fractures diffusion equation:

$$
\phi_{f} \rho_{f} c_{f g} \frac{\partial p_{f}}{\partial t}-\nabla \cdot\left(-\frac{\rho_{f} k_{f}}{\mu_{f}} \nabla p_{f}\right)=Q_{p}
$$

Considering the continuity of pressure on the boundaries of $\Gamma_{2}$ and $\Gamma_{3}$, as well as the initial condition, an improved mathematical model of the SRV region is developed: 


$$
\begin{aligned}
& \int\left[\phi_{m} \rho_{m} C_{m g}+\left(1-\phi_{m}\right) \frac{\rho_{s} M_{g} V_{L}}{V_{s t d}} \cdot \frac{p_{m}}{\left(1+K(T) \cdot p_{m}\right)^{2}}\right] \frac{\partial p_{m}}{\partial t}-\nabla \cdot\left[\frac{\rho_{m} k_{m}}{\mu_{m}} \nabla p_{m}\right] \\
& =\left(1-\phi_{m}\right) \frac{\rho_{s} M_{g} V_{L}}{V_{s t d}} \cdot \frac{p_{m}}{\left(1+K(T) \cdot p_{m}\right)^{2}} \cdot K(T) \cdot\left[-\frac{1}{2 T}+\frac{E}{R T^{2}}\right] \cdot \frac{\partial T}{\partial t}-Q_{p} \\
& \left\{\phi_{f} \rho_{f} c_{f g} \frac{\partial p_{f}}{\partial t}-\nabla \cdot\left(-\frac{\rho_{f} k_{f}}{\mu_{f}} \nabla p_{f}\right)=Q_{p}\right. \\
& \left.p_{m}\right|_{t=0}=\left.p_{f}\right|_{t=0}=p_{i} \\
& \left.p_{f}(x, y, z ; t)\right|_{\Gamma_{3}}=\left.p_{a}(x, y, z ; t)\right|_{\Gamma_{3}} \\
& \left.p_{m}(x, y, \mathrm{z} ; \mathrm{t})\right|_{\Gamma_{2, S \mathrm{SRV}}}=\left.p_{m}(x, y, \mathrm{z} ; \mathrm{t})\right|_{\Gamma_{2, \text { OSRV }}}
\end{aligned}
$$

$\Gamma_{2}, \Gamma_{3}$ is defined as the boundary of the SRV region, the boundary between hydraulic and natural fracture respectively.

\subsection{The OSRV model}

The matrix characteristics of the outside stimulated reservoir volume (OSRV) region are the same as those of matrix system of the SRV region. Viscosity flow, Knudsen diffusion and adsorption/desorption are considered in the model. The pressure of OSRV matrix is equal to $\Gamma_{2}$. Considering the closed outer boundary, the mathematical model of OSRV is established.

$$
\begin{aligned}
& \int\left[\phi_{m} \rho_{m} C_{m g}+\left(1-\phi_{m}\right) \frac{\rho_{s} M_{g} V_{L}}{V_{s t d}} \cdot \frac{p_{m}}{\left(1+K(T) \cdot p_{m}\right)^{2}}\right] \frac{\partial p_{m}}{\partial t}-\nabla \cdot\left[\frac{\rho_{m} k_{m}}{\mu_{m}} \nabla p_{m}\right] \\
& \left\{\begin{array}{l}
=\left(1-\phi_{m}\right) \frac{\rho_{s} M_{g} V_{L}}{V_{s t d}} \cdot \frac{p_{m}}{\left(1+K(T) \cdot p_{m}\right)^{2}} \cdot K(T) \cdot\left[-\frac{1}{2 T}+\frac{E}{R T^{2}}\right] \cdot \frac{\partial T}{\partial t} \\
p_{m}(x, y, z ; t=0)=p_{i}
\end{array}\right. \\
& \left.\frac{\partial p_{m}}{\partial n}\right|_{\Gamma_{1}}=0 \\
& \left(\left.p_{m}(x, y, \mathrm{z} ; \mathrm{t})\right|_{\Gamma_{2, S \mathrm{SRV}}}=\left.p_{m}(x, y, \mathrm{z} ; \mathrm{t})\right|_{\Gamma_{2, \text { OSRV }}}\right.
\end{aligned}
$$

$\Gamma_{1}$ represents the outer boundary of the gas reservoir.

\subsection{The heat diffusion equation of the shale reserve}

Heat constantly transfers to the outer boundary during the process of hydraulic fracture heating. Assuming that the hydraulic fracture temperature has little variation, the hydraulic fracture is considered to be an isothermal heat source. Heat propagation in the formation can be characterized by the thermal diffusion equation. Heat transfer varies in different media.

(1) Matrix framework

Heat transfer in matrix framework mainly via heat conduction and the diffusion equation can be represented as follows (Chen et al., 2013; Wang et al., 2014)

$$
\left(1-\phi_{m}\right) \rho_{s} c_{m} \frac{\partial T_{m}}{\partial t}+\left(1-\phi_{m}\right) \nabla \cdot\left(-K_{m} \nabla T_{m}\right)=0
$$

(2) Matrix pores 
Heat transfer through gas in matrix pores relies on heat conduction and heat convection (Chen et al., 2013; Wang et al., 2014).

$$
\phi_{m} \rho_{m} c_{g} \frac{\partial T_{g}}{\partial t}+\phi_{m} \nabla \cdot\left(-K_{g} \nabla T_{g}\right)+\rho_{m} c_{g} v_{m} \cdot \nabla T_{g}=0
$$

(3) Natural fractures

Heat propagation in natural fractures appears the same as with matrix pores. Heat conduction and heat convection are two main modes of heat transfer.

$$
\phi_{f} \rho_{f} c_{g} \frac{\partial T_{g}}{\partial t}+\phi_{f} \nabla \cdot\left(-K_{g} \nabla T_{g}\right)+\rho_{g} c_{g} v_{f} \cdot \nabla T_{f}=0
$$

In the above equation, $T_{m}$ and $T_{g}$ respectively represent the temperature of the matrix framework and methane, $\mathrm{K}$; Setting $T_{m}=T_{g}=T$ by assuming there is local thermal equilibrium at the pores wall. $c_{m}$ and $c_{g}$ refer to the heat capacity at constant pressure of the matrix framework and gas phase, respectively, $\mathrm{J} \cdot \mathrm{kg}^{-1} \cdot \mathrm{K}^{-1} ; K_{m}$ and $K_{g}$ refer to thermal conductivity of the matrix framework and gas respectively, $\mathrm{W} \cdot \mathrm{m}^{-1} \mathrm{~K}^{-1} ; v_{m}$ and $v_{f}$ represent the flow velocity in matrix and natural fractures, respectively, $\mathrm{m} \cdot \mathrm{s}^{-1}$.

$$
\left\{\begin{array}{l}
v_{m}=-\frac{k_{m}}{\mu_{m}} \nabla p_{m} \\
v_{f}=-\frac{k_{f}}{\mu_{f}} \nabla p_{f}
\end{array}\right.
$$

Thermal continuity condition on the boundary of the SRV region $\left(\Gamma_{2}\right)$ and the thermal insulating condition on the outer boundary of the gas reservoir $\left(\Gamma_{1}\right)$ are considered in the thermal recovery model.

\subsection{Numerical solution}

The above equations are solved using the PDE module, the Fluid Flow module and the Heat Transfer module of COMSOL Multiphysics (commercial software, which can directly implement partial differential equations and initial-boundary conditions). The time-dependent solver-backward differentiation formula (BDF) is used to solve the fully coupled model. Direct (UMFPACK) is used as the system solver in this work.

\section{Results and discussion}

In this section, we investigate how heating a hydraulic fracture can impact shale gas recovery. Additionally, the impact of shale thermal properties, Langmuir volume, facture spacing, bottom hole pressure (BHP), matrix intrinsic permeability and the SRV region area on thermal recovery were analyzed. The basic parameters for the simulation are given in Table 1.

Table 1 Simulation parameters of thermal recovery

\begin{tabular}{|l|l|l|l}
\hline Parameter & Value & Unit & Definition \\
\hline$L$ & 800 & $\mathrm{~m}$ & length of horizontal well \\
\hline$p_{i}$ & 15 & $\mathrm{MPa}$ & initial pressure \\
\hline$p_{w}$ & 3.5 & $\mathrm{MPa}$ & bottom hole pressure \\
\hline
\end{tabular}




\begin{tabular}{|l|l|l|l|}
\hline$k_{m i}$ & $2 \times 10^{-19}$ & $\mathrm{~m}^{2}$ & matrix intrinsic permeability \\
\hline$\varphi_{m}$ & 0.05 & - & matrix porosity \\
\hline$d f$ & 0.005 & $\mathrm{~m}$ & aperture of hydraulic fracture \\
\hline$x_{f}$ & 100 & $\mathrm{~m}$ & half-length of hydraulic fracture \\
\hline$y_{f}$ & 50 & $\mathrm{~m}$ & spacing between hydraulic fracture \\
\hline$h_{f}$ & 50 & $\mathrm{~m}$ & height of hydraulic fracture \\
\hline$N$ & - & - & number of hydraulic fracture \\
\hline$a$ & 0.1 & $\mathrm{~m}$ & spacing of natural fracture \\
\hline$b$ & $5 \times 10^{-6}$ & $\mathrm{~m}$ & aperture of natural fracture \\
\hline$V_{L}$ & 0.0283 & $\mathrm{~m} / \mathrm{kg}$ & Langmuir volume constant \\
\hline$\rho_{s}$ & 2600 & $\mathrm{~kg} / \mathrm{m}^{3}$ & density of formation rock \\
\hline$T_{c}$ & 191.05 & $\mathrm{~K}$ & critical temperature \\
\hline$P_{c}$ & 4.64 & $\mathrm{MPa}$ & critical pressure \\
\hline$c_{m}$ & 1000 & $\mathrm{~J} /(\mathrm{K} \cdot \mathrm{Kg})$ & heat capacity of matrix framework \\
\hline$K_{m}$ & 3 & $\mathrm{~W} /(\mathrm{m} \cdot \mathrm{K})$ & thermal conductivity of matrix framework \\
\hline$E$ & -9209 & $\mathrm{~J} / \mathrm{mol}$ & adsorption energy \\
\hline$k_{0}$ & 0.1 & $\mathrm{MPa}-1$ & pre-exponential constant independent temperature \\
\hline$T_{0}$ & 338 & $\mathrm{~K}$ & initial temperature \\
\hline$T_{a}$ & 478 & $\mathrm{~K}$ & temperature of hydraulic fracture \\
\hline & & & \\
\hline
\end{tabular}

\subsection{Evaluation of thermal recovery}

Fig. 3 demonstrates that during the whole process of hydraulic fractures heating, heat constantly transferring to the SRV boundary. After 30 years of production, the whole SRV region almost reaches the same temperature. Fig. 4 shows that hydraulic fracture heating can actually enhance shale gas recovery from long-term production prospective. With increasing stimulation temperature, more gas can be extracted. Compared to the no heating condition $(T=338 \mathrm{~K})$, approximately $27 \%(T=408 \mathrm{~K})$, and $42 \%(T=478 \mathrm{~K})$ additional gas can be recovered after 30 years of thermal recovery.

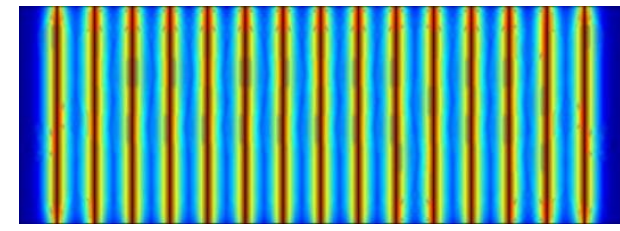

(a) 3.1 years

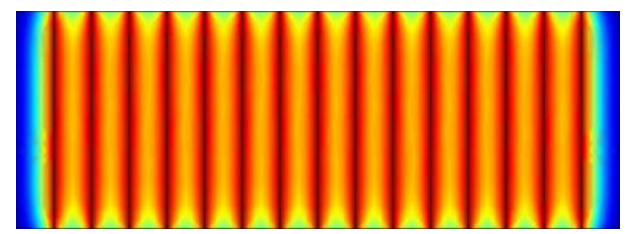

(c) 9.3 years

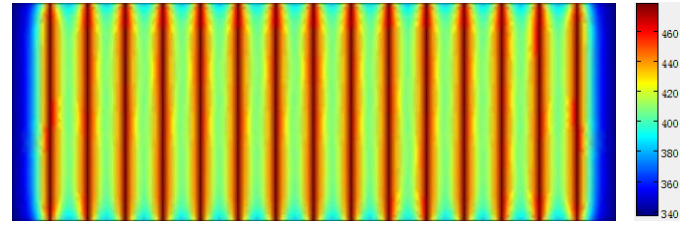

(b) 6.2 years

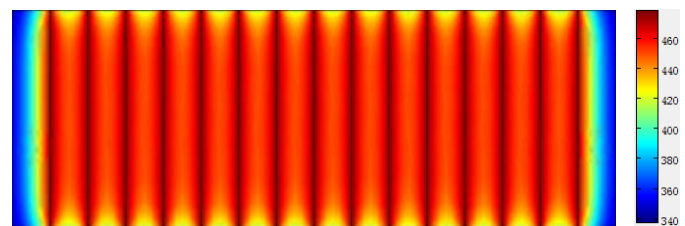

(d) 12.4 years 


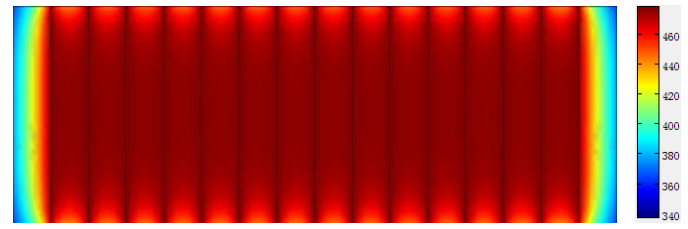

(f) 30 years

(e) 15.5 years

$\mathrm{V}$ region

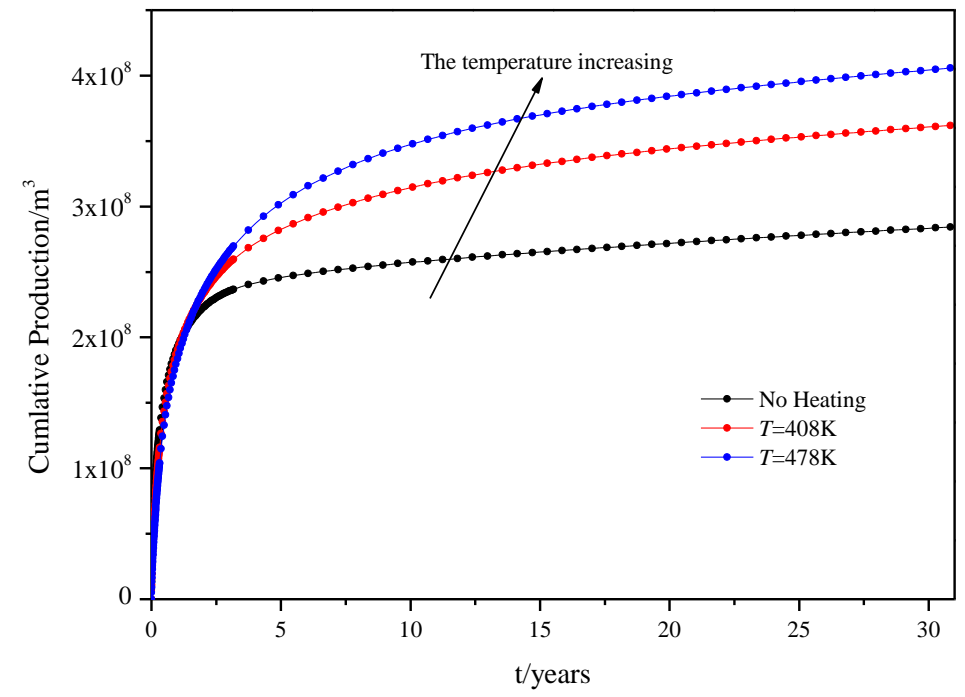

Fig. 4. Cumulative production with different stimulation temperature

Fig. 5 demonstrates that hydraulic fracture heating has little effect on cumulative free gas production, but it can greatly enhance cumulative adsorbed gas production. With higher thermal energy inputs, more adsorbed gas can be recovered. During the initial production period, free gas in the natural fractures mainly contributes to the cumulative production, which was slightly affected slightly by temperature. After a period of production, the interporosity flow allowed gas to flow from matrix into the natural fractures; high temperature can promote the gas desorbed from the surface of the matrix. Therefore, the difference between heating and no heating increased with continuous production. Additionally, the difference expands with the stimulation temperature increasing.

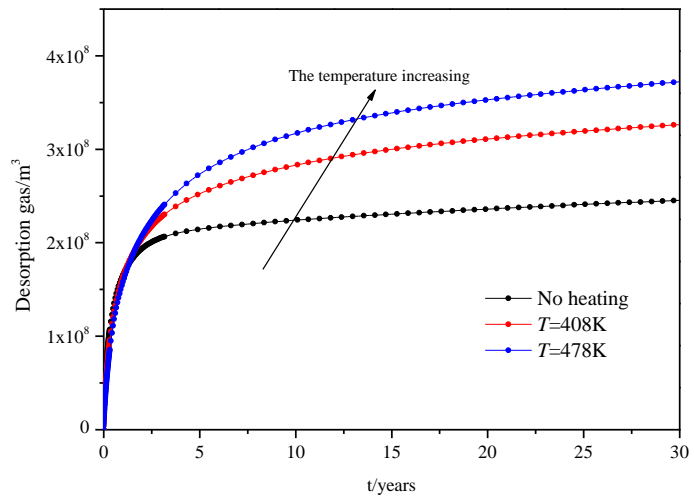

(a) Adsorbed gas

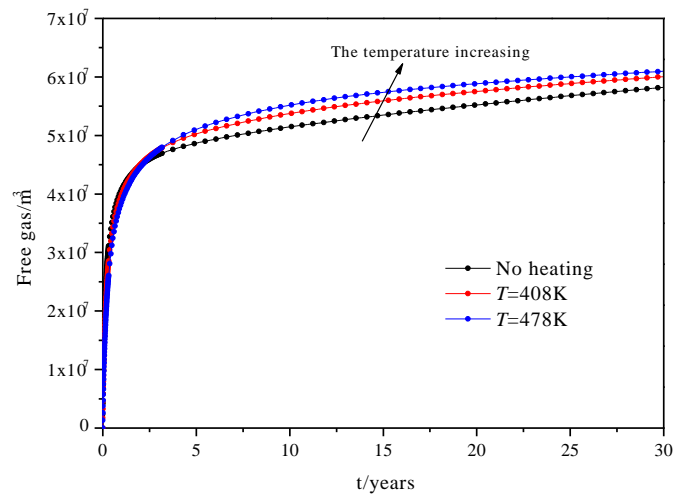

(b) Free gas

Fig. 5. Cumulative production of adsorbed gas and free gas with different simulation temperature 
(a) 0.6 years (heating)

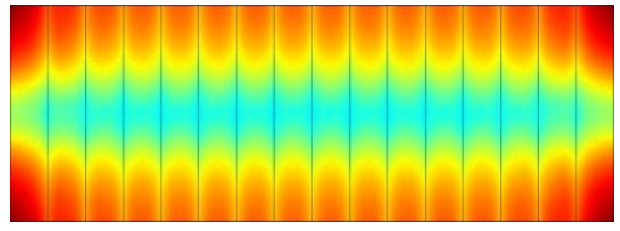

(a) 1.6 years (heating)

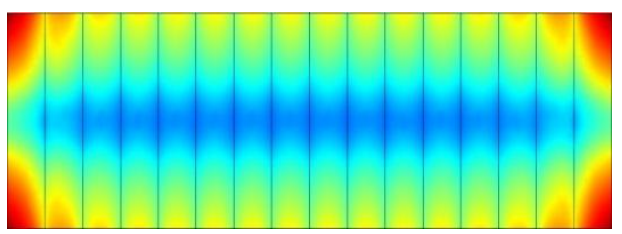

(a) 6.3 years (heating)

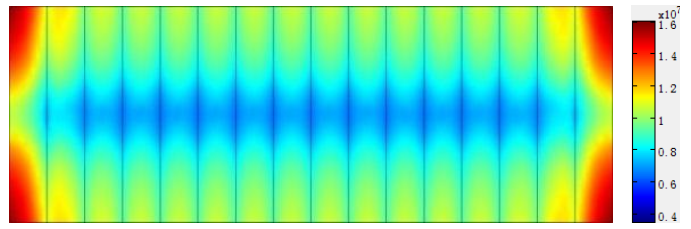

(b) 0.6 years (no heating)

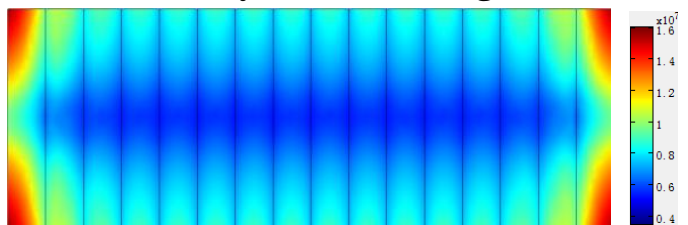

(b) 1.6 years (no heating)

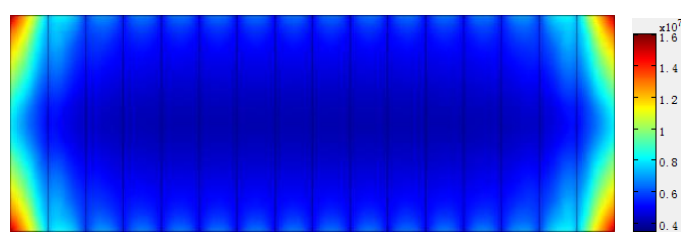

(b) 6.3 years (no heating)

Fig. 6. Pressure distribution of the SRV region with and without thermal treatment

Fig. 6 shows the pressure distribution of the SRV region with and without thermal treatment; it can be observed that pressure propagates faster in the case without heating. This is because thermal treatment promotes large amount of gas desorbed from the matrix surface, and the desorption gas provides a self-induced pressure maintenance effect to alleviate the rate of pressure propagation.

\subsection{Sensitivity analysis}

\subsubsection{Shale thermal properties}

The thermal properties of formation, including matrix heat capacity and heat conductivity may affect the efficiency of the thermal stimulation. These properties are relative to formation composition, porosity, clay content and even temperature and pressure. To investigate the possible influences of those properties, different matrix heat capacity and heat conductivity values of the matrix (Gilliam and Morgan, 1987) are set to model the long-term production of the horizontal well. 


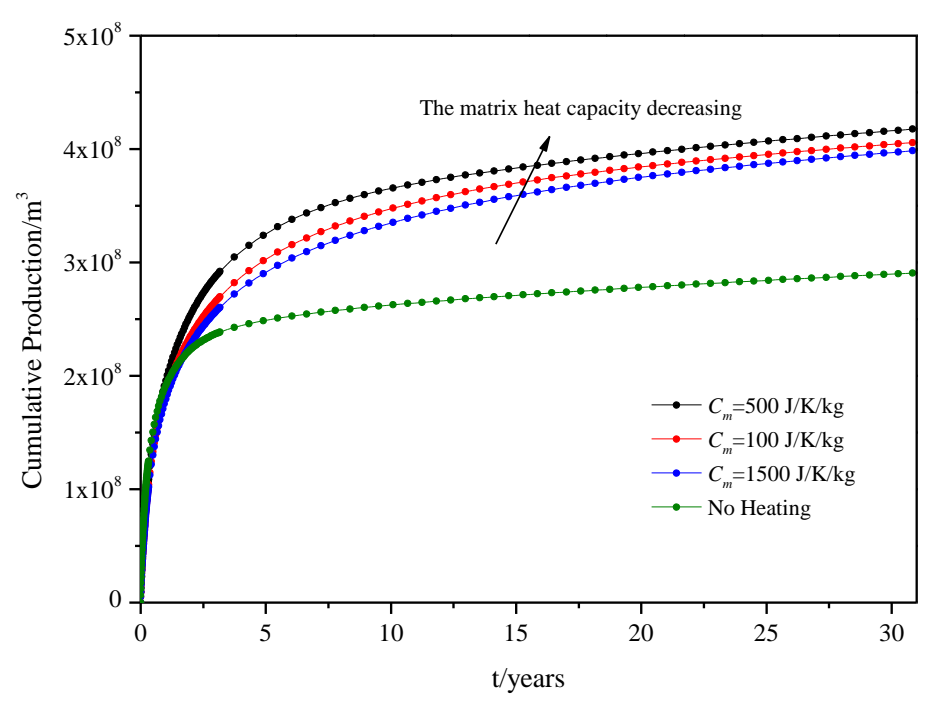

Fig. 7. Effect of matrix heat capacity on cumulative production

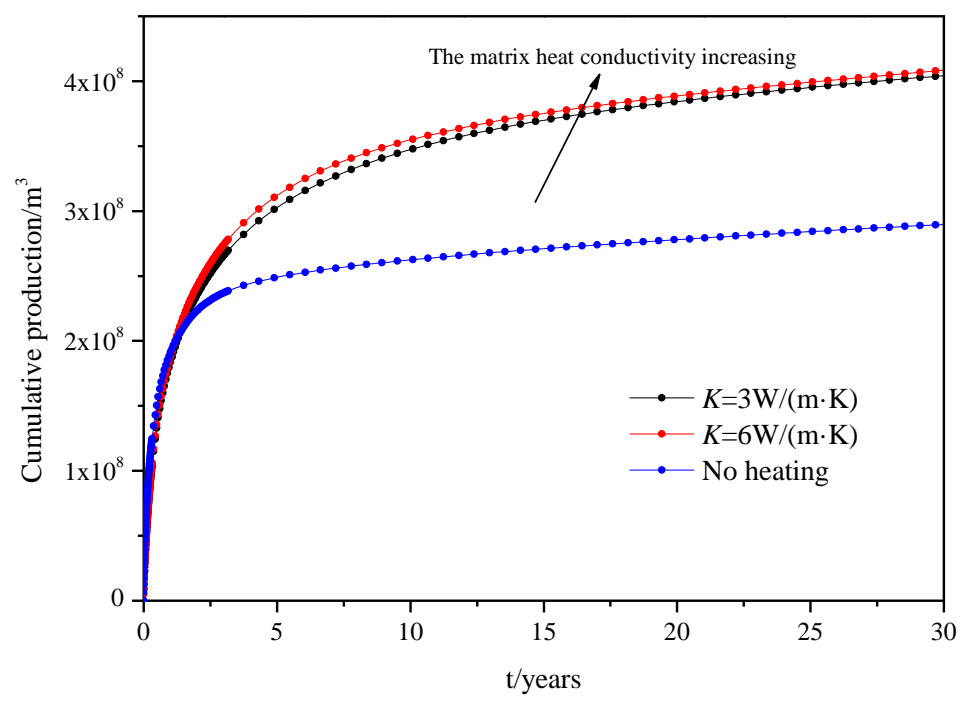

Fig. 8. Effect of matrix heat conductivity on cumulative production

Fig. 7 indicates the impact of matrix heat capacity on cumulative production. The heat capacity has a limited effect on the middle stages of production and has a negligible effect on the cumulative production after 30 years of production because the whole SRV region will be heated up to a desired temperature regardless of the formation capacity if given enough time for heat diffusion process to occur. However, although matrix heat capacity will not have a substantial difference in the cumulative production while the fracture temperature is kept constant, it has a huge impact on how much energy is required to heat up the formation. The smaller the heat capacity is, the less input energy is required for heating the formation. Fig. 8 demonstrates that heat conductivity has little effect on cumulative production except in a 3-10 year window. The greater the heat conductivity is, the more adsorbed gas is recovered.

\subsubsection{Langmuir volume}

The adsorption of methane on the matrix surface can be described by the Langmuir isotherm equation. The Langmuir volume, $V_{L}$, determines how much gas can be ultimately adsorbed by the rock matrix, which reflects the shale formation's intrinsic adsorption capacity. To investigate the effect of adsorption and desorption on the thermal recovery, three cases of different Langmuir volumes $\left(V_{L}=0.7 \times 10^{-2}, 1.4 \times 10^{-2}, 2.8 \times 10^{-2}\right)$ are simulated; the solution is 
presented in Fig. 9.

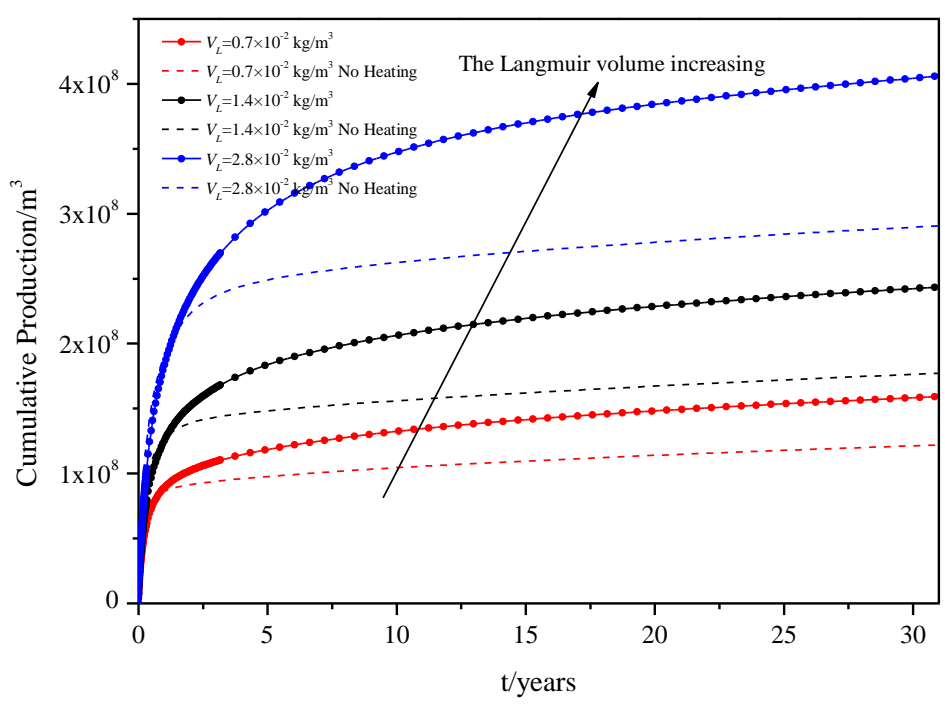

Fig. 9 Effect of Langmuir volume on cumulative production

In the case of no thermal treatment, higher cumulative production is observed with greater Langmuir volume, as shown in Fig. 9. Considerable improvement is observed in gas recovery through heating hydraulic fractures compared with no thermal treatment on the same Langmuir volume. Additionally, less adsorption gas initially occurs with lower Langmuir volumes, and less additional recovery is achieved by heating the formation. After 30 years of production, approximately $29 \%\left(V_{L}=2.8 \times 10^{-2} \mathrm{~kg} / \mathrm{m}^{3}\right), 27 \%\left(V_{L}=1.4 \times 10^{-2} \mathrm{~kg} / \mathrm{m}^{3}\right)$, and $23 \%$ $\left(V_{L}=0.7 \times 10^{-2} \mathrm{~kg} / \mathrm{m}^{3}\right)$ additional gas is recovered by thermal stimulation. Thus, when TOC content is low which indicates a low Langmuir volume to some extent, thermal stimulation is not recommend for enhancing gas recovery.

\subsubsection{Fracture spacing}

In keeping the area of the SRV region constant, three cases of different fracture spacing $(D=50 \mathrm{~m}, 100 \mathrm{~m}, 150 \mathrm{~m})$ are simulated to evaluate the performance of hydraulic fracture heating.

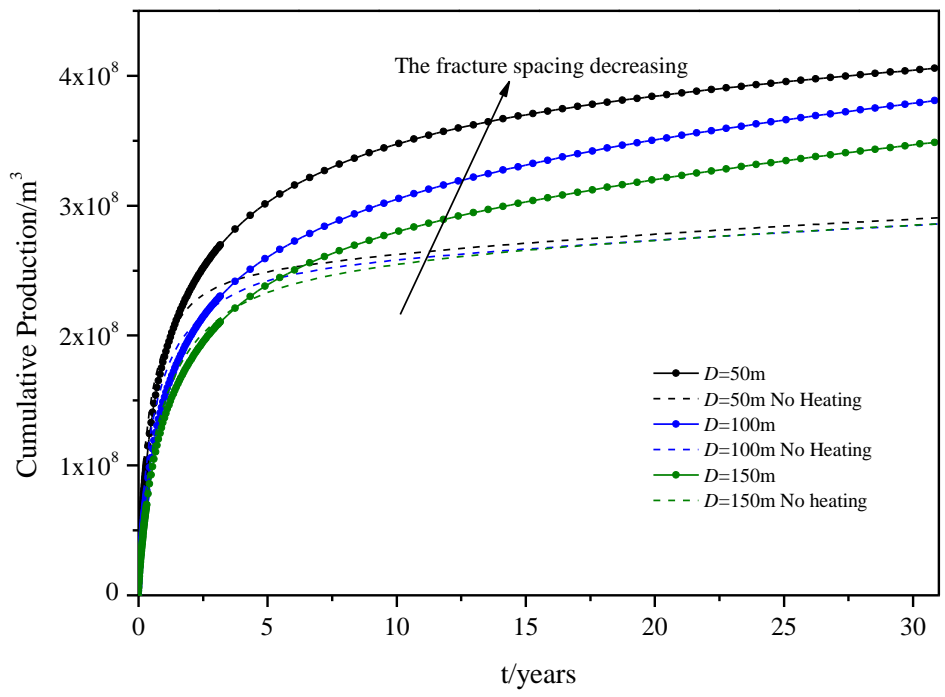

Fig. 10. Effect of fracture spacing on cumulative production

Fig. 10 demonstrates the effect of fracture spacing on cumulative production with and without thermal treatment. Obviously, in the early stage of production, small fracture spacing 
leads to high cumulative production under the condition of no heating. However, it has a negligible effect on the long-term production because after sufficient production time, the gas in the whole SRV region is almost extracted regardless of fracture spacing. Obvious improvement of cumulative production can be noticed in Fig. 10 by heating the formation. With the $478 \mathrm{~K}$ of stimulation temperature, approximately $40 \%$ additional gas $(D=50 \mathrm{~m})$ is recovered after 30 years of production. The smaller the fracture spacing, the more energy is injected into the formation, which indicates that more gas will be desorbed from the matrix surface and the extra recovery will be higher.

\subsubsection{Bottom hole pressure}

During the realistic development process, which is limited to surface production conditions and constraints on wellhead flowing pressure, the BHP is high. Less adsorbed gas can be liberated due to high average SRV region pressure, leading to a low production rate of the fractured horizontal well. Thermal stimulation may be a perfect choice to promote more gas release from the matrix surface. To investigate the potential of hydraulic fracture heating, possible $\mathrm{BHP}(\mathrm{BHP}=1.7 \mathrm{MPa}, 3.5 \mathrm{MPa}, 7 \mathrm{MPa})$ is used to mimic long-range well production. The results are shown in Fig. 11.

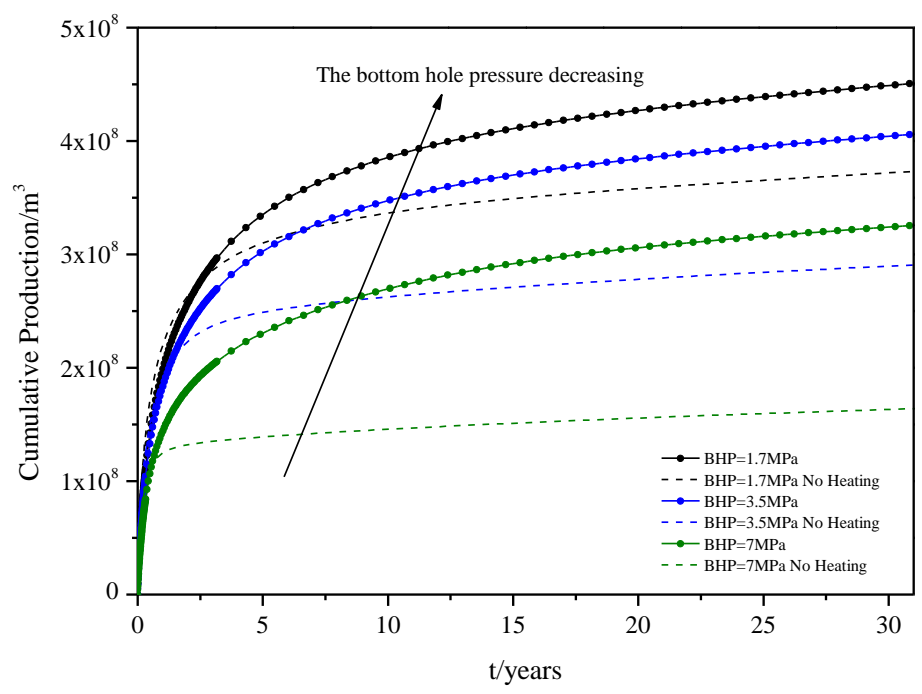

Fig. 11. Effect of BHP on cumulative production

It can be observed that approximately $98 \%, 39 \%$, and $20 \%$ additional gas is produced when the $\mathrm{BHP}$ is $7 \mathrm{MPa}, 3.5 \mathrm{MPa}$, and $1.7 \mathrm{MPa}$ respectively after 30 years of recovery. Thus, when well production rate is low due to high BHP, thermal recovery can be considered for its potential in accelerating the gas released from the matrix. Of course, the formation must contain rich TOC.

\subsubsection{Matrix intrinsic permeability}

Shale gas reservoir has extremely low permeability, estimated approximately 4 to 200 nano-Darcy, which fundamentally determines the horizontal well production performance. The ultralow shale matrix permeability contributes to the long period of time for a well to produce gas in transient flow regimes, and the average pressure in SRV may not be low enough to allow for sufficient gas to be desorbed from the matrix surface. By comparing the cumulative production of three different matrix permeability $\left(k_{m}=800 \mathrm{nD}, 200 \mathrm{nD}, 2 \mathrm{nD}\right)$ with and without thermal treatment, this paper explores the possible method to enhance shale gas 
reservoir recovery.



Fig. 12 Effect of matrix permeability on cumulative production

Fig. 12 demonstrates the simulation results. The results show that matrix permeability dominates the transient flow in the formation; at lower the permeability, which can alleviate the pressure diffusion process, less gas is produced. When heating the hydraulic fracture, recovery is actually improved; the low permeability responds to more additional desorption gas. However, the difference of extra recovered gas among different matrix permeability is small.

\subsubsection{SRV region area}

Rock brittleness is the key mechanical rock parameter in hydraulic fracturing, and it determines the scale of the fracture network. Shale brittleness depends on the brittle mineral content, the elasticity modulus and Poisson's ration; it has a positive correlation with the quartz, feldspar and calcite content, and it can be calculated using the elasticity modulus and Poisson's ratio. High rock brittleness complicates fracture geometrical morphology and large SRV region area. To investigate the effect of the SRV region area on cumulative production with and without thermal treatment, three scenarios of different SRV region area $\left(\mathrm{SRV}=400 \times 100 \times 50 \mathrm{~m}^{3}, 800 \times 200 \times 50 \mathrm{~m}^{3}, 1600 \times 400 \times 50 \mathrm{~m}^{3}\right)$ are simulated. The results are shown in Fig. 13. 


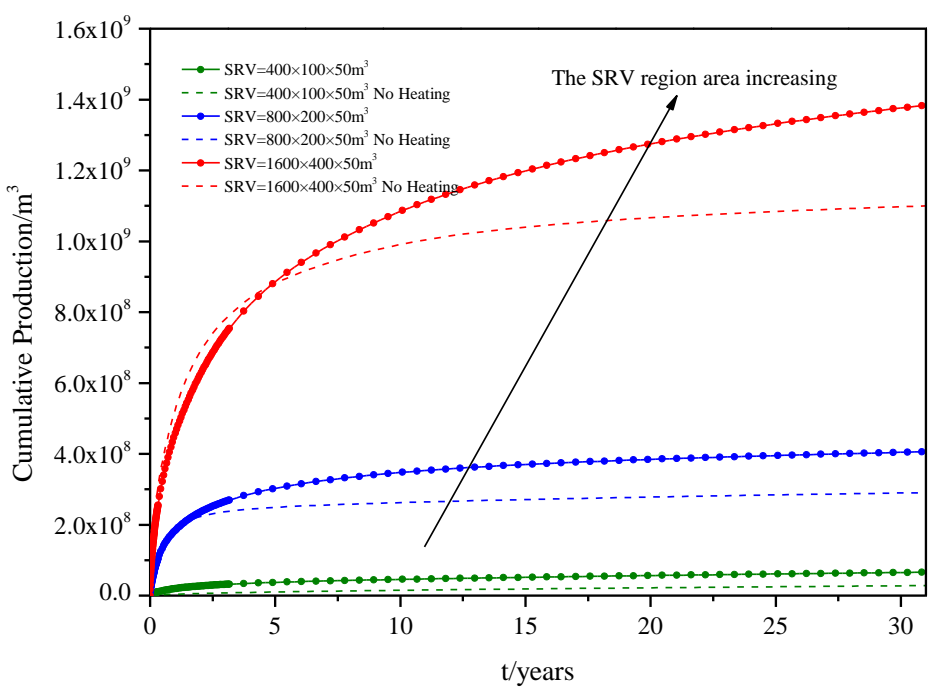

Fig. 13. Effect of SRV region area on cumulative production

It is obvious that cumulative production has a positive correlation with the SRV region area with and without thermal recovery; Additionally, with a greater SRV region area, more extra recovery is achieved, which is due to the high potential of thermal treatment. Thus, it is necessary to take shale mechanical properties and brittleness into consideration because they determine fracture propagation, final micro-fractures scale and the area of the SRV region during the shale gas reservoir development process regardless of whether thermal treatment is employed. Another interesting phenomenon is that the cumulative production without thermal treatment is higher than that with thermal treatment in the early stage. The gap also becomes larger with increasing fracturing scale. The reason is as follows. In the early stage, the gas produced mainly comes from the free gas in the natural fractures. With the rising of temperature, the viscosity of gas increased (only under relatively low pressure). Thus, the flow resistance increased, which indicates low production under the condition of thermal treatment. After a period of depletion, the average pressure decreases to a level at which gas is liberated from the rock matrix. At this stage, the thermal treatment would be advantageous in the development of the shale gas reservoir. Based on the above, we can conclude that thermal recovery is more suitable for long-term production of shale gas reservoir, and it still requires further study based on the theory of maximizing the net present value (NPV) of the assets.

\section{Conclusions}

This paper developed a fully coupled numerical model of fractured horizontal well in the shale gas reservoir to investigate the potential of thermal recovery based on hydraulic fracture heating and the factors that impact the effectiveness of thermal stimulation. Discrete fracture, dual continuum media and single porosity media are employed to describe hydraulic fractures, the SRV region and the matrix, respectively. The model also incorporates known non-linear flow mechanisms, such as adsorption/desorption, Knudsen diffusion, non-Darcy flow and pressure dependent phenomenon, as well as heat diffusion processes within the shale reserve. Then, the effectiveness of formation factors on thermal recovery is analyzed. The specific conclusions of this study are summarized below:

1. Heating hydraulic fractures can actually enhance shale gas recovery by altering gas desorption behavior. More adsorbed gas is recovered at a higher stimulation temperature. The 
method of thermal recovery is more suitable for long-term production from an economic perspective, and it still need further study based on the theory of maximize NPV of the assets.

2. The thermal properties of the shale formation have only a limited impact on long-term production. Gas recovery is primarily determined by simulation temperature, matrix adsorption ability, fracture spacing, the SRV region area, BHP and reservoir permeability. A shale gas reservoir with large Langmuir volume and SRV region area, relatively small fracture spacing, and a high bottom hole pressure has the potential for thermal treatment to enhance gas recovery.

3. The fracture temperature, the area of the SRV region and the fracture spacing are the only three factors that can be controlled during the design and execution of thermal treatment in the field.

\section{Acknowledgments}

The authors thank the National Natural Science Foundation Key Program of China (No.51234007, No.51504276, No.51504277), the China Postdoctoral Science Foundation (2014M551989, 2015T80762), the National Science Foundation for Young Scientists of China (No.51404291), National Science and Technology Major Project (No.2011ZX05044), Innovative Project of China University of Petroleum(YCX2015018)for supporting this work.

\section{Nomenclature}

$\beta \quad$ Forchheimer coefficient, $\mathrm{m}^{-1}$

$\delta$ non-Darcy flow correction factor, dimensionless

$\rho_{a}$ gas density in hydraulic fracture, $\mathrm{kg} / \mathrm{m}^{3}$

$\varphi_{a}$ porosity of hydraulic fracture, dimensionless

$q_{a}$ source/sink term, $\mathrm{kg} / \mathrm{s}$

$\mu_{a}$ gas viscosity in hydraulic fractures, $\mathrm{Pa} \cdot \mathrm{s}$

$v_{a}$ gas flow velocity, $\mathrm{m} / \mathrm{s}$

$k_{a}$ permeability in hydraulic fracture, $\mathrm{m}^{2}$

$M_{g}$ methane molar weight, $\mathrm{kg} / \mathrm{mol}$

$T$ gas reservoir temperature, $\mathrm{K}$

$Z \quad Z$ factor, dimensionless

$C_{a g}$ gas compressibility factor in the hydraulic fracture, $\mathrm{Pa}^{-1} \cdot \mathrm{s}$

$p_{i}$ initial pressure, $\mathrm{Pa}$

$p_{w}$ bottom hole pressure, $\mathrm{Pa}$

$D_{k m} \quad$ Knudsen diffusivity in matrix, $\mathrm{m}^{2} / \mathrm{s}$

$N_{k}$ mass flow caused by Knudsen diffusion, $\mathrm{kg} /\left(\mathrm{m}^{2} \cdot \mathrm{s}\right)$

$C_{m}$ gas molar concentration, $\mathrm{mol} / \mathrm{m}^{3}$

$\varphi_{m}$ matrix porosity, dimensionless;

$\mathrm{R}$ universal gas coefficient, $8.314 \mathrm{~K}^{-1} \cdot \mathrm{mol}^{-1}$

$k_{m i}$ intrinsic permeability of matrix, $\mathrm{m}^{2}$

$c_{k}$ a constant value at 1

$F_{m}$ gas mass flow rate of the matrix, $\mathrm{kg} /\left(\mathrm{m}^{2} \cdot \mathrm{s}\right)$

$k_{m}$ the matrix permeability, $\mathrm{m}^{2}$ 
$q_{a d s}$ gas adsorption mass per unit volume of formation, $\mathrm{kg} / \mathrm{m}^{3}$

$K(T)$ adsorption equilibrium equation constant, $1 / \mathrm{Pa}$;

$E$ characteristic adsorption energy, $\mathrm{J} / \mathrm{mol}$

$V_{L} \quad$ Langmuir volume, $\mathrm{m}^{3} / \mathrm{kg}$

$\rho_{s}$ shale matrix density, $\mathrm{kg} / \mathrm{m}^{3}$

$V_{\text {std }}$ molar volume under standard condition, $\mathrm{m}^{3} / \mathrm{mol}$

$k_{f 0}$ intrinsic permeability of natural fractures, $\mathrm{m}^{2}$

$T_{m}$ temperature of the matrix framework, $\mathrm{K}$

$T_{g} \quad$ temperature of the methane, $\mathrm{K}$

$L$ length of horizontal well, $\mathrm{m}$

$d f$ aperture of hydraulic fracture, $\mathrm{m}$

$x_{f}$ half-length of hydraulic fracture, $\mathrm{m}$

$h_{f}$ height of hydraulic fracture, $\mathrm{m}$

$y_{f}$ spacing between hydraulic fracture, $\mathrm{m}$

$N$ number of hydraulic fracture

$a$ spacing of natural fractures, $\mathrm{m}$

$b$ aperture of natural fractures, $\mathrm{m}$

$T_{c}$ critical temperature of the methane, $\mathrm{K}$

$P_{c} \quad$ critical pressure of the methane, $\mathrm{Pa}$

\section{Reference}

Adamson, A., Gast, A., 1997. Physical chemistry of surfaces.

Akkutlu, I.Y., Fathi, E., 2012. Multiscale gas transport in shales with local Kerogen heterogeneities. SPE Journal 17, 1,002-001,011.

Chalmers, G.R., Bustin, R.M., 2008. Lower Cretaceous gas shales in northeastern British Columbia, Part II: evaluation of regional potential gas resources. Bulletin of Canadian Petroleum Geology 56, 22-61.

Chen, B., Song, E., Cheng, X., 2013. Plane-Symmetrical Simulation of Flow and Heat Transport in Fractured Geological Media: A Discrete Fracture Model with Comsol, Multiphysical Testing of Soils and Shales. Springer pp. 149-154.

Civan, F., 2010. Effective correlation of apparent gas permeability in tight porous media. Transport in porous media $82,375-384$.

Curtis, J.B., 2002. Fractured shale-gas systems. AAPG bulletin 86, 1921-1938.

Dean, R., Lo, L., 1988. Simulations of naturally fractured reservoirs. SPE reservoir engineering 3, 638-648.

Dong, J.-J., Hsu, J.-Y., Wu, W.-J., Shimamoto, T., Hung, J.-H., Yeh, E.-C., Wu, Y.-H., Sone, H., 2010. Stress-dependence of the permeability and porosity of sandstone and shale from TCDP Hole-A. International Journal of Rock Mechanics and Mining Sciences 47, 1141-1157.

Dongyan, F., Jun, Y., Hai, S., Hui, Z., Wei, W., 2015. A composite model of hydraulic fractured horizontal well with stimulated reservoir volume in tight oil \& gas reservoir. Journal of Natural Gas Science and Engineering 24, 115-123.

Eshkalak, M.O., Aybar, U., Sepehrnoori, K., 2014. An integrated reservoir model for unconventional resources, coupling pressure dependent phenomena, SPE Eastern Regional Meeting. Society of Petroleum Engineers 
Evans, R.D., Civan, F., 1990. Characterization of non-Darcy multiphase flow in petroleum bearing formations. Oklahoma Univ., Norman, OK (USA). School of Petroleum and Geological Engineering. Freeman, C., Moridis, G., Blasingame, T., 2011. A numerical study of microscale flow behavior in tight gas and shale gas reservoir systems. Transport in porous media 90, 253-268.

Fu, Y., Yang, Y.-K., Deo, M., 2005. Three-dimensional, three-phase discrete-fracture reservoir simulator based on control volume finite element (CVFE) formulation, SPE Reservoir Simulation Symposium. Society of Petroleum Engineers

Geiger-Boschung, S., Matthäi, S.K., Niessner, J., Helmig, R., 2009. Black-oil simulations for three-component, three-phase flow in fractured porous media. SPE journal 14, 338-354.

Ghoodjani, E., Kharrat, R., Vossoughi, M., Bolouri, S.H., 2012. A review on thermal enhanced heavy oil recovery from fractured carbonate reservoirs, SPE Heavy Oil Conference Canada. Society of Petroleum Engineers.

Gilliam, T., Morgan, I., 1987. Shale: Measurement of thermal properties. Oak Ridge National Lab., TN (USA)

Hildenbrand, A., Krooss, B., Busch, A., Gaschnitz, R., 2006. Evolution of methane sorption capacity of coal seams as a function of burial history - a case study from the Campine Basin, NE Belgium. International Journal of Coal Geology 66, 179-203.

Hoda, N., Fang, C., Lin, M., Symington, W., Stone, M., 2010. Numerical modeling of ExxonMobil's Electrofrac field experiment at Colony Mine.

Javadpour, F., Fisher, D., Unsworth, M., 2007. Nanoscale gas flow in shale gas sediments. Journal of Canadian Petroleum Technology 46.

Karimi-Fard, M., Firoozabadi, A., 2001. Numerical simulation of water injection in 2D fractured media using discrete-fracture model, SPE annual technical conference and exhibition. Society of Petroleum Engineers.

Karimi-Fard, M., Firoozabadi, A., 2003. Numerical simulation of water injection in fractured media using the discrete-fracture model and the Galerkin method. SPE Reservoir Evaluation \& Engineering 6, 117-126.

Kast, W., Hohenthanner, C.-R., 2000. Mass transfer within the gas-phase of porous media. International Journal of Heat and Mass Transfer 43, 807-823.

Lee, A.L., Gonzalez, M.H., Eakin, B.E., 1966. The viscosity of natural gases. Journal of Petroleum Technology 18, 997-991,000.

Mahmoud, M., 2014. Development of a new correlation of gas compressibility factor (Z-factor) for high pressure gas reservoirs. Journal of Energy Resources Technology 136, 012903.

Martini, A.M., Walter, L.M., Ku, T.C., Budai, J.M., McIntosh, J.C., Schoell, M., 2003. Microbial production and modification of gases in sedimentary basins: A geochemical case study from a Devonian shale gas play, Michigan basin. AAPG bulletin 87, 1355-1375.

McLennan, J.D., Tran, D.T., Zhao, N., Thakur, S.V., Deo, M.D., Gil, I.R., Damjanac, B., 2010. Modeling fluid invasion and hydraulic fracture propagation in naturally fractured formations: a three-dimensional approach, SPE International Symposium and Exhibiton on Formation Damage Control. Society of Petroleum Engineers.

Moinfar, A., Varavei, A., Sepehrnoori, K., Johns, R.T., 2013. Development of a coupled dual continuum and discrete fracture model for the simulation of unconventional reservoirs, SPE Reservoir Simulation Symposium. Society of Petroleum Engineers.

Mutyala, S., Fairbridge, C., Paré, J.J., Bélanger, J.M., Ng, S., Hawkins, R., 2010. Microwave 
applications to oil sands and petroleum: A review. Fuel Processing Technology 91, 127-135.

Ross, D.J., Bustin, R.M., 2007. Shale gas potential of the lower jurassic gordondale member, northeastern British Columbia, Canada. Bulletin of Canadian Petroleum Geology 55, 51-75.

Ruthven, D.M., 1984. Principles of adsorption and adsorption processes. John Wiley \& Sons

Soeder, D.J., 1988. Porosity and permeability of eastern Devonian gas shale. SPE Formation Evaluation 3, 116-124.

Sun, H., Yao, J., Gao, S.-h., Fan, D.-y., Wang, C.-c., Sun, Z.-X., 2013. Numerical study of CO 2 enhanced natural gas recovery and sequestration in shale gas reservoirs. International Journal of Greenhouse Gas Control 19, 406-419.

Symington, W., 2006. ExxonMobil's electrofrac process for in situ oil shale conversion 26th Oil Shale Symposium. Colorado School of Mines.

Symington, W.A., Burns, J.S., El-Rabaa, W., Otten, G.A., Pokutylowicz, N., Spiecker, P.M., Williamson, R.W., Yeakel, J.D., 2009. Field testing of Electrofrac ${ }^{\mathrm{TM}}$ process elements at ExxonMobil's Colony Mine, 29th Oil Shale Symposium, Colorado School of Mines, Golden. Colorado.

Thomas, L.K., Dixon, T.N., Pierson, R.G., 1983. Fractured reservoir simulation. Society of Petroleum Engineers Journal 23, 42-54.

Thoram, S., Ehlig-Economides, C.A., 2011. Heat Transfer Applications for the Stimulated Reservoir Volume (Srv), SPE Annual Technical Conference and Exhibition. Society of Petroleum Engineers.

Wang, H., Ajao, O., Economides, M.J., 2014. Conceptual study of thermal stimulation in shale gas formations. Journal of Natural Gas Science and Engineering 21, 874-885.

Warren, J., Root, P.J., 1963. The behavior of naturally fractured reservoirs. Society of Petroleum Engineers Journal 3, 245-255.

Wu, Y.-S., Li, J., Ding, D., Wang, C., Di, Y., 2014. A generalized framework model for the simulation of gas production in unconventional gas reservoirs. SPE Journal 19, 845-857.

Yahya, N., Kashif, M., Nasir, N., Akhtar, M.N., Yusof, N.M., 2012. Cobalt ferrite nanoparticles: an innovative approach for enhanced oil recovery application, Journal of Nano Research. Trans Tech Publ, pp. 115-126.

Zhao, N., McLennan, J.D., Deo, M.D., 2011. Morphology and Growth of Fractures in Unconventional Reservoirs, Canadian Unconventional Resources Conference. Society of Petroleum Engineers. 